\title{
Study of a Parabolic Trough Adequate for the CERER Site (Dakar-Senegal)
}

\author{
Awa Mar ${ }^{1,2}$, Serigne Thiao ${ }^{1,2}$, Cheikh Mbow ${ }^{3}$ and Issakha Youm ${ }^{1,2}$ \\ 1. CERER (Center of Studies and Research on Renewable Energies), Dakar BP. 476, Senegal \\ 2. Laboratory of Solar Energy, Materials and Systems, Department of Physics, Faculty of Sciences and Technology, University \\ Cheikh anta Diop of Dakar, Senegal \\ 3. Laboratory of Fluid Mechanical and Hydraulic, Department of Physics, Faculty of Sciences and Technology, University Cheikh \\ Anta Diop of Dakar, Senegal
}

Received: March 04, 2016 / Accepted: March 16, 2016 / Published: May 31, 2016.

\begin{abstract}
This study presents the modeling of a parabolic trough solar collector. The main objective is to show the influences of the parabolic trough sensor effective efficiency (concentrator optical efficiencies of transmission, reflection, geometrical and the receiver absorption coefficient), of its length, of the mass flow rate on temperatures distributions of the heat fluid and the receiver and on thermal global efficiency (solar conversion efficiency into energy usable). The atmospheric parameters are those of Senegal in April. A prototype existing in the CERER (Center of Studies and Research on Renewable Energies) (Dakar-Senegal) is given as example of application.
\end{abstract}

Key words: Parabolic trough solar collector, receptor, efficiency, temperature, fluid.

\section{Nomenclature \\ Bi Biot number \\ $c_{p, f} \quad$ Specific mass heat capacity at constant pressure \\ $D \quad$ Hydraulic diameter of the absorber tube \\ F Shape factor \\ Gz Graetz number \\ $h_{\text {conv }}$ Coefficient of forced convection of the heat fluid \\ $h_{v} \quad$ Coefficient of external mixed convection \\ DNI Direct normal insolation \\ $l_{\text {conc }} \quad$ Width of the concentrator \\ $l_{r} \quad$ Perimeter of receiver tube \\ $L_{\text {conc }} \quad$ Length of the concentrator \\ $\dot{m} \quad$ Mass flow rate of the fluid \\ $P_{m} \quad$ Wetted perimeter of the absorber tube \\ Pr Prandtl number \\ $\dot{Q}_{\text {conc }}$ Thermal power emitted by the concentrator and \\ received by the receiver \\ $\dot{Q}_{\text {conv }}$ Thermal power lost by convection \\ $\dot{Q}_{f} \quad$ Thermal power received by the heat fluid}

Corresponding author: Awa Mar, $\mathrm{PhD}$, research fields: energy conversion and thermal solar.

$\begin{array}{ll}\dot{Q}_{r} & \begin{array}{l}\text { Thermal power transmitted from the receiver to the } \\ \text { engine heat exchanger }\end{array} \\ \dot{Q}_{r a y} & \text { Thermal power lost by radiation } \\ \dot{Q}_{s} & \begin{array}{l}\text { Thermal power emitted by the sun and received by } \\ \text { the concentrator }\end{array} \\ R e & \text { Reynolds number } \\ S & \text { Fluid passage section } \\ S_{\text {conc }} & \text { Opening surface of the concentrator } \\ S_{m} & \text { Wetted surface of the receiver tube } \\ S_{r} & \text { Surface of receiving envelope } \\ t & \text { Time } \\ T_{0} & \text { Ambient temperature } \\ T_{f} & \text { Average temperature of the heat fluid in the tube } \\ T_{f}(x) & \text { Local temperature of the heat fluid } \\ T_{i n} & \text { Input temperature of the heat fluid in the tube } \\ T_{o u t} & \text { Output temperature of the heat fluid in the tube } \\ T_{p} & \text { Average temperature of the wall of the receiver tube } \\ T_{p}(x) & \text { Local temperature of the wall of the receiver tube } \\ T_{r} & \text { Average temperature of the receiving envelope } \\ U(r) & \text { Component of the velocity of the heat fluid } \\ <U> & \text { Avending to } x\end{array}$




$\begin{array}{ll}\alpha_{\text {conc }} & \text { Geometric concentration ratio } \alpha_{\text {conc }}=\frac{S_{c o n c}}{S_{r}} \\ \alpha_{r} & \text { Absorption coefficient of the receiver tube } \\ \varepsilon & \text { Emissivity coefficient of the receiver tube } \\ \zeta_{c o n c} & \text { Geometrical efficiency of the concentrator } \\ \kappa_{P T} & \text { Effective efficiency of the PT (parabolic trough) } \\ \lambda & \text { Thermal conductivity of the fluid } \\ \mu & \text { Dynamic viscosity of the fluid } \\ \eta_{c o n c} & \text { Optical efficiency of the concentrator } \\ \eta_{t h-P T} & \text { Thermal global efficiency of the PT } \\ \rho_{c o n c} & \text { Optical efficiency of reflection } \\ \sigma_{S B} & \text { Stefan Boltzmann constant } \\ \tau_{c o n c} & \text { Optical efficiency of transmission }\end{array}$

\section{Introduction}

In developing countries like Senegal, the production of clean energy that promotes sustainable development alternative to depletable energy sources such as gas or oil is a major issue. Currently the only technological responses to this requirement are the use of generators consuming fossil fuels or photovoltaic cells associated with batteries [1]. Solar thermal energy consists in using the heat from the solar radiation to heat a fluid at high temperature rather than the radiation itself. If the fluid temperature is so high, it can then activate a thermodynamic cycle to generate electricity. This sector is that of the concentrated solar power. The Sahelian-subsaharan countries with a favorable geographical location have a real solar potential with nearly 3,000 hours/year of radiation to reach high temperatures that remain unavoidable for solar energy production by thermodynamic way. One of the selective criteria is a simple technology to realize and its performances and costs able to be competitive with photovoltaic systems [2].

Specific components of concentrated solar power system are generally: the concentrator or collector, the receiver, the thermodynamic cycle and possibly a thermal storage or hybridization. The insolations are concentrated on a horizontal receiving tube in which circulates a heat transfer fluid whose temperature usually reaches $673 \mathrm{~K}$. This fluid is then pumped through heat exchangers to produce superheated steam which activates a turbine or an electric generator [3].

This study is about the sensor relative to the concentration of solar radiation. It is where is done the thermal conversion of solar radiation into usable heat. Its performances determine the overall efficiency of the solar power plant [4]. In order to proceed to an energy analysis of the PT (parabolic trough), a realistic model allowed to focus on temperatures distributions of the heat fluid and the receiver and on thermal global efficiency (solar conversion efficiency into energy usable) according on the parabolic trough effective efficiency, its length and the mass flow rate. Solar tangor sensor is designed by way of application.

\section{Analytical Modelling}

The parabolic trough is constituted by an absorbent cavity with superficial treatment with very high absorption and heat-thin allowing to neglect the thermal conduction [5]. The absorber is protected by a coaxial borosilicate envelope tube with stagnant air and very low iron content which prevents the dispersion of heat into the atmosphere, suggesting that the temperature of the receiving envelope is equal to the temperature of the wall of the receiver tube, $T_{r}=T_{p}$. The whole, called receiver is placed on the optical focal axis of a specular parabolic curved solar reflector at very high degree of reflection. The concentrator focuses the DNI (direct normal insolation) towards the receiver to allow it reaching high temperatures [6]. The collector is oriented north-south and tracks the sun continuously. To find temperatures fields of the heat fluid and the receiver wall, we start from the energy balance equation on a volume element at the receiver tube.

We recognize that:

- The inertia effects of the absorber and the fluid (considered as an ideal gas with constant physical properties) are negligible; 
- The absorber is heat-thin $(B i<0.1)$;

- Theoptical efficiency of the concentrator $\eta_{\text {conc }}$ considered is independent of the concentration geometrical ratio $\alpha_{\text {conc }}$.

$$
\eta_{\text {conc }}=\tau_{\text {conc }} \rho_{\text {conc }} \zeta_{\text {conc }}
$$

where, $\tau_{c o n c}$ is optical efficiency of transmission, $\rho_{\text {conc }}$ is optical efficiency of reflection, $\zeta_{\text {conc }}$ is geometrical efficiency of the concentrator.

To find the equation that governs the operation of the heat absorber, we assume energy balance on the elementary surface $\mathrm{d} S=2 \pi R \mathrm{~d} x$ of the tube. It comes then:

$$
\dot{Q}_{c o n c}=\dot{Q}_{c o n v}+\dot{Q}_{r a y}+\dot{Q}_{f}
$$

With:

$$
\begin{gathered}
\dot{Q}_{c o n c}=\alpha_{r} \eta_{c o n c} D N I \cdot S_{c o n c} \\
\dot{Q}_{r a y}=\sigma F \varepsilon S_{r}\left(T_{r}^{4}-T_{0}^{4}\right) \\
\dot{Q}_{f}=h_{c o n v} S_{m}\left(T_{p}(x)-T_{f}(x)\right) \\
\dot{Q}_{c o n v}=h_{v} S_{r}\left(T_{r}(x)-T_{0}\right)
\end{gathered}
$$

Supposing that $T_{r}(x)=T_{p}(x)$, we obtain:

$$
\begin{gathered}
\kappa_{P T} D N I \cdot l_{\text {conc }}=h_{\text {conv }} P_{m}\left(T_{p}(x)-T_{f}(x)\right) \\
+h_{v} l_{r}\left(T_{p}(x)-T_{0}\right) \\
+\epsilon \sigma F l_{r}\left(T_{p}(x)^{4}-T_{0}{ }^{4}\right)
\end{gathered}
$$

where, $T_{0}$ is the ambient air temperature, $\kappa_{P T}=$ $\alpha_{r} \eta_{\text {conc }}$ is the PT effective efficiency, depend only on the PT intrinsic characteristics.

$T_{f}(x)$ is the average temperature of the fluid in the abscissa $x$ defined by:

$$
\begin{gathered}
<U>T_{f}(x)= \\
\frac{1}{\pi R^{2}} \iint_{r=0, \theta=0}^{r=R, \theta=2 \pi} U(r) \cdot T_{f}(r, \theta, x) r \mathrm{~d} r \mathrm{~d} \theta
\end{gathered}
$$

Supposing that, the flow is hydro-dynamically established and unidirectional transfers. Under these conditions, the integration of the heat equation in the elementary volume $\mathrm{d} V=\pi R^{2} \mathrm{~d} x$ leads to:

$$
\dot{m} c_{p, f} \frac{\mathrm{d} T_{f}}{\mathrm{~d} x}=h_{\text {conv }} P_{m}\left(T_{p}(x)-T_{f}(x)\right)
$$

Thus the PT operating is governed by the following system of equation:

$$
\left\{\begin{array}{c}
\kappa_{P T} D N I \cdot l_{\text {conc }}=h_{\text {conv }} P_{m}\left(T_{p}(x)-T_{f}(x)\right) \\
+h_{v} l_{r}\left(T_{p}(x)-T_{0}\right) \\
+\epsilon \sigma F l_{r}\left(T_{p}(x)^{4}-T_{0}{ }^{4}\right) \\
\dot{m} c_{p, f} \frac{\mathrm{d} T_{f}}{\mathrm{~d} x}=h_{\text {conv }} P_{m}\left(T_{p}(x)-T_{f}(x)\right)
\end{array}\right.
$$

The exchange coefficient by forced convection $h_{\text {conv }}$ for an internal flow is defined by:

$$
h_{\text {conv }}=\frac{\lambda N u}{D}
$$

Several correlations are supposed depending on the cases of air flow in a circular tube of finite length with:

If $R e<R e c$, laminar flow;

If $G \mathrm{z}<100$, we use Hausen relation [7]:

$$
N u=3.66+\frac{0.0668 \mathrm{Gz}}{1+0.04(G z)^{2 / 3}}
$$

If $G z>100$, we use Sieder and Tate relation [7]:

$$
N u=1.6(G z)^{1 / 3}
$$

If $R e>R e c$, turbulent flow we use Dittus-Boelter relation [7]:

$$
N u=0.023 \operatorname{Re}^{0.8} \operatorname{Pr}^{0.4}
$$

With:

$$
\begin{gathered}
\operatorname{Pr}=\frac{C_{p} \mu}{\lambda} \\
\operatorname{Re}=\frac{\dot{m} D}{\mu S} \\
G z=\operatorname{Re} \cdot \operatorname{Pr} \cdot \frac{D}{L}
\end{gathered}
$$

To solve the problems of atmospheric air in contact with horizontal walls, the McAdams and Woertz formulation is the most used [8]:

$$
h_{v}=3.86 \mathrm{~V}+5.67
$$

Supposing:

$$
\begin{gathered}
\dot{Q}_{s}=D N I \cdot S_{\text {conc }} \\
\dot{Q}_{r}=\dot{Q}_{c o n c}-h_{v} S_{r}\left(T_{r}-T_{0}\right)- \\
\sigma_{S B} F \varepsilon S_{r}\left(T_{r}^{4}-T_{0}^{4}\right) \\
\eta_{t h-P T}=\frac{\dot{Q}_{r}}{\dot{Q}_{s}}
\end{gathered}
$$

The differential Eq. (9) was integrated owing to a predictor-corrector scheme (Heun scheme) of second order [9]. The iterative Newton-Raphson method is 
used to solve the non-linear Eq. (10) because of the term $T^{4}$.

\section{Results and Discussions}

This study was realized on the site of the CERER (Center of Studies and Research on Renewable Energies) in Dakar Hann Equipe (Senegal) located by the following geographical coordinates: $14^{\circ} 43^{\prime} 11^{\prime \prime}$ North, $17^{\circ} 26^{\prime} 24^{\prime \prime}$ West and $35 \mathrm{~m}$ of elevation.

Contrary to the flat plate solar collectors that benefit from global solar radiation, the main input variable of any CSP (concentrated solar power) system is the DNI [10]. By satellite measurements, the atlas data PVGIS (photovoltaic geographical information system) allowed us to estimate the site's energy potential [11]. The ambient temperature $T_{0}$ and the wind velocity set respectively at $300 \mathrm{~K}$ and $5 \mathrm{~m} \cdot \mathrm{s}^{-1}$ are the usual climatic conditions in Dakar, the DNI is equal to $799 \mathrm{~W} \cdot \mathrm{m}^{-2}$.

\subsection{Influences of the PT Intrinsic Characteristics}

The variations of the output temperature $T_{\text {out }}$ and the thermal global efficiency $\eta_{t h-P T}$ (solar conversion efficiency into energy usable) depending on the PT effective efficiency $\kappa_{P T}$ are shown in Fig. 1.

The output temperature of the fluid $T_{\text {out }}$ increases with the coefficient $\kappa_{P T}$. Just as the PT thermal global efficiency $\eta_{t h-P T}$ which follows a linear form:

$$
\begin{aligned}
\eta_{t h-P T} & =a \cdot \kappa_{P T} \\
a & \approx 0.2
\end{aligned}
$$

Indeed, losses caused by the geometrical defects must be as low as possible to maximize the performances of the PT. Similarly the optical efficiency of reflection $\rho_{\text {conc }}$, which determines the quantity of radiation received by the receiver, compared to the incident radiation on the concentrator must be optimized. The transmission factor $\tau_{\text {conc }}$ and absorption coefficient $\alpha_{r}$ should be improved.

For this, the blocks of reflective surfaces must be well assembled and set moving in order to track the sun. To reach high temperatures, it is necessary to

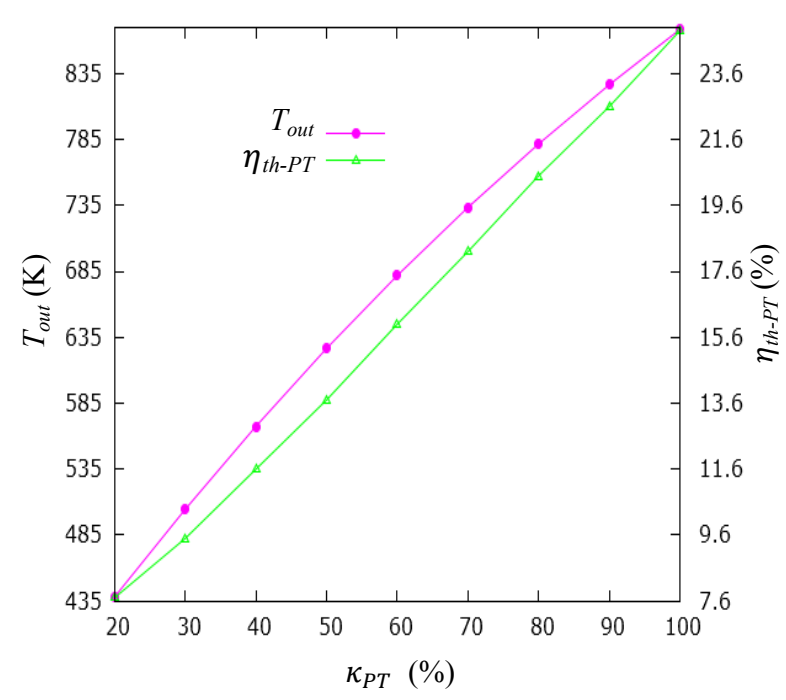

Fig. 1 Variations of $T_{\text {out }}$ and $\eta_{t h-P T}$ according to $\kappa_{P T}$ with $\dot{m}=0.001 \mathrm{~kg} \cdot \mathrm{s}^{-1}$.

concentrate the radiation by a surface with extreme reflectivity with a best technico-economic compromise [12].

In order to increase the temperature of the heat fluid, it is necessary to isolate the absorber with a glass envelope while leaving the concentrated radiation to return. The glass prevents the diffused rays to leave by performing "the greenhouse effect". Fragile glass can be replaced by some polymer film [13]. But the major disadvantage of these materials is the deterioration of their properties under the effect of the ultraviolet rays. To improve the heat transfer, the absorber must have a high coefficient of absorption and be painted in perfect black. They are also investigations on potential of using two tubular receivers in one compound parabolic concentrator [14].

\subsection{Influences of the PT Length}

Fig. 2 represents temperatures progression of the wall receiver tube $T_{p}$ and of the heat fluid $T_{f}$ according to the concentrator length $L_{c o n c}$, its width $l_{\text {conc }}$ being fixed.

We note that, the temperature profiles are on this form:

$$
T_{i}\left(L_{\text {conc }}\right) \approx \frac{T_{i}(0)}{1-a_{i}} \cdot\left[1-a_{i} \cdot e^{-b_{i} \cdot L_{c o n c}}\right]
$$




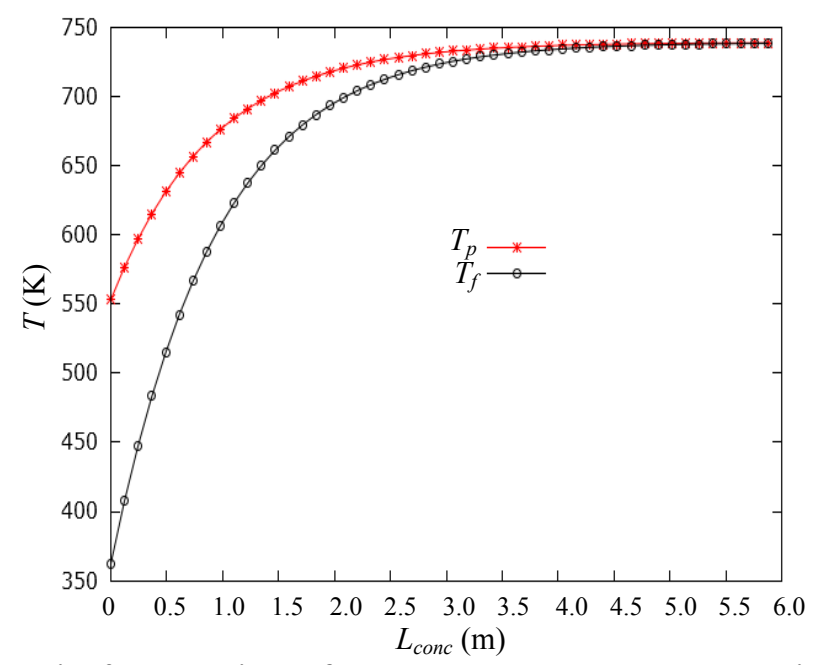

Fig. 2 Evolutions of temperatures $T_{p}$ and $T_{f}$ according to $L_{\text {conc }}$ with $\dot{m}=0.001 \mathrm{~kg} \cdot \mathrm{s}^{-1}$.

(i) is relative to the wall or to the fluid, $a_{i}$ and $b_{i}$ are positive constants, $T_{i}(0)$ represents the teperatures at the input.

Thus a first approximation, we can assume that, the non linear terms in the energy balance at the receiver (radiative effects) can be neglected. Fig. 2 shows also that, the temperature of the fluid tends to that of the receiving wall and that beyond $L_{e} \approx 3.5 \mathrm{~m}$, we can assume that, the fluid flow regime is thermally established. It results that, if $L_{\text {conc }} \geq L_{e}$, so $T_{f}\left(L_{\text {conc }}\right) \approx T_{p}\left(L_{\text {conc }}\right) \approx T_{p}\left(L_{e}\right)$. Then for this environmental conditions, set the length of the PT to $4.0 \mathrm{~m}$ is reasonable because nearly all energy of receiver is recovered by the heat fluid.

On the other hand, when the length of the receiver is less than $2.0 \mathrm{~m}$, the PT is inefficient for solar thermodynamic applications because the output temperature is too low (less than $673 \mathrm{~K}$ ).

\subsection{Influences of the Heat Fluid Flow Rate}

Figs. 3 and 4 show the influence of mass flow rate on the heat transfer between the receiver wall, and the heat fluid particularly temperatures change between the wall and the fluid.

Heat transfer from the wall towards the fluid being done by forced convection, the expression of the coefficient of transfer $h_{\text {conv }}$ depends only on Reynolds number $R e$ characteristic of the flow regime.

We considered suitable correlations according to the case. The Reonly depends on the mass flow rate $\dot{m}$ with air used as fluid heat considered such as a perfect gas with constant physical properties.

Fig. 3 is laminar flow case, the very low flow rates provide a thermally established regime with relatively high temperatures. In contrast these flow rates do not represent great interest because they are quasi-static, and consequently the quantity of heat collected at output of the tube is insignificant. The range of low

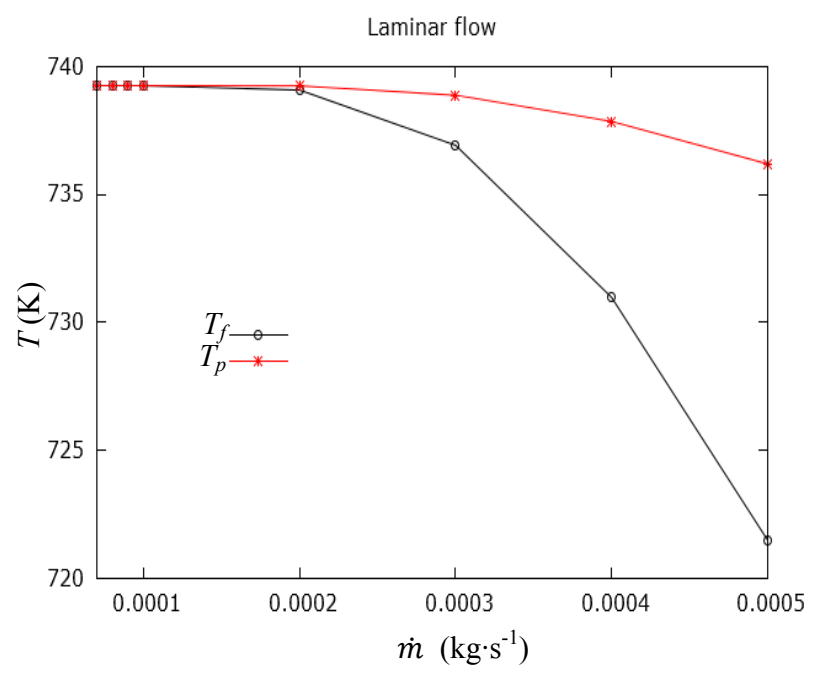

Fig. 3 Evolutions of $T_{p}$ and $T_{f}$ according to $\dot{m}$ : laminar

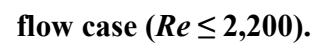

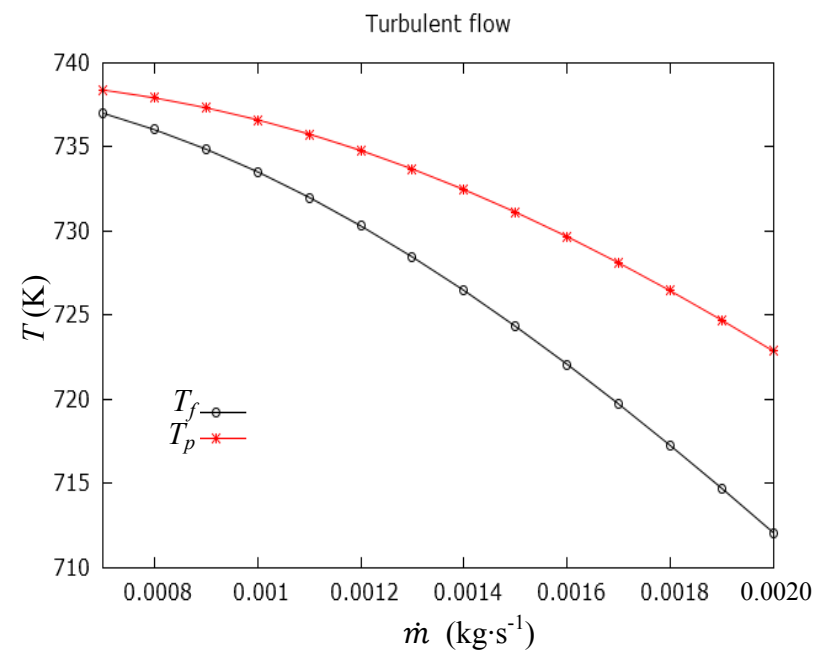

Fig. 4 Evolutions of $T_{p}$ and $T_{f}$ according to $\dot{m}$ : turbulent flow case $(\operatorname{Re}>3,000)$. 
flow rates considered $\left(\sim 0.3 \times 10^{-3} \mathrm{~kg} \cdot \mathrm{s}^{-1}\right.$ to $\left.0.5 \times 10^{-3} \mathrm{~kg} \cdot \mathrm{s}^{-1}\right)$ shows a large temperature difference between the wall and the fluid (going up to $\sim 15^{\circ} \mathrm{C}$ ).

Fig. 4 is turbulent flow case, the temperature difference between the wall and the fluid is minimal for low to moderate flows $\left(0.8 \times 10^{-3} \mathrm{~kg} \cdot \mathrm{s}^{-1} \leq \dot{m}<\right.$ $\left.1.4 \times 10^{-3} \mathrm{~kg} \cdot \mathrm{s}^{-1}\right)$. In contrast for high flow rates $(\dot{m} \geq$ $\left.1.8 \times 10^{-3} \mathrm{~kg} \cdot \mathrm{s}^{-1}\right)$, this difference reaches high values in the order of $10^{\circ} \mathrm{C}$.

For this type of system, the turbulent flow regime for exchanges by forced convection between the wall receiver and the fluid is the most favorable, but the rates of flow must be moderate or low [2]. This is what led us to work thereafter with rate mass flow $\dot{m}$ of $0.001 \mathrm{~kg} \cdot \mathrm{s}^{-1}$.

\subsection{Sample Application Choice of Solar Tangor} Sensor

The previous results have allowed us to adopt the solar tangor sensor (Fig. 5).

The solar tangor sensor is constituted by an absorbent cavity with superficial treatment with very high absorption. The absorber is protected by a coaxial borosilicate envelope tube with stagnant air, and very low iron content which prevents the dispersion of heat into the atmosphere. Geometric and optical characteristics of the PT are recorded in Table 1.

The evolutions of the DNI and the output temperature of the fluid $T_{f}\left(L_{\text {conc }}\right)=T_{\text {out }}$ during a typical day of April (the sunniest month) are given in Fig. 6 [15].

The evolutions of the DNI and the output temperature $T_{\text {out }}$ are similar, indicating that, the power received by the receiving surface is the most important factor on the performances of the system. A maximum temperature of $733 \mathrm{~K}$ is reached with a DNI of $799 \mathrm{~W} \cdot \mathrm{m}^{-2}$.

Fig. 7 is a 3D representation of the receiver wall temperatures $T_{p}$ depending on the "Time" and along the receiver tube $x$. The example is taken for a typical day of April. Output temperatures are highest between

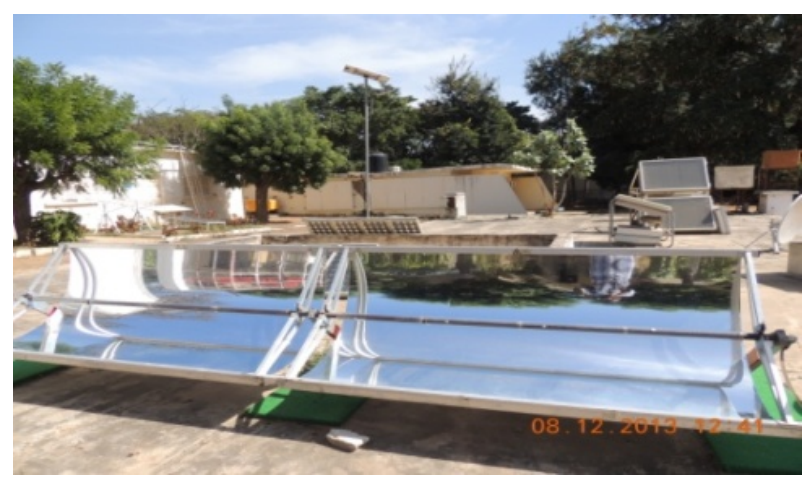

Fig. 5 Solar tangor sensor.

Table 1 PT characteristics.

\begin{tabular}{ll}
\hline Parameters & Values \\
\hline$L_{\text {conc }}$ & $4.10 \mathrm{~m}$ \\
$l_{\text {conc }}$ & $1.25 \mathrm{~m}$ \\
$l_{r}$ & $5.2 \times 10^{-2} \mathrm{~m}$ \\
$P_{m}$ & $3.4 \times 10^{-2} \mathrm{~m}$ \\
$\kappa_{P T}$ & 0.85 \\
\hline
\end{tabular}

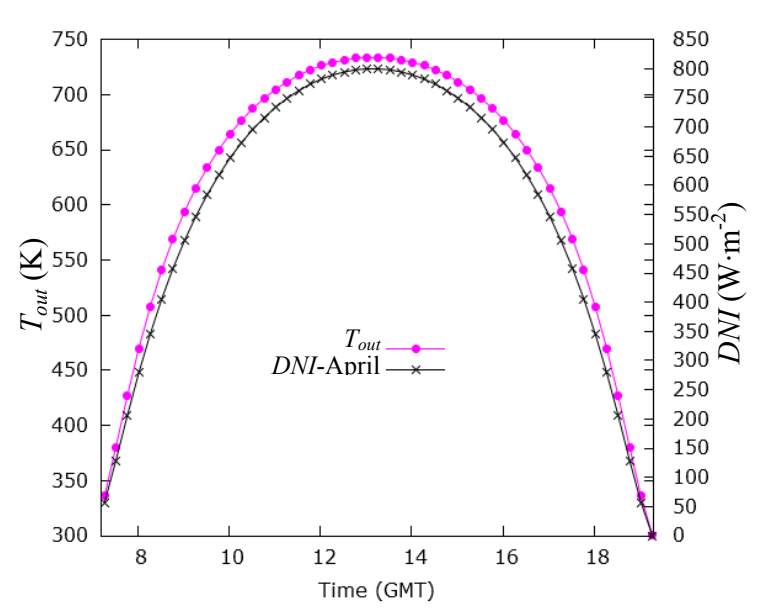

Fig. 6 Evolutions of the $D N I$ and $T_{\text {out }}$ during typical day of April.

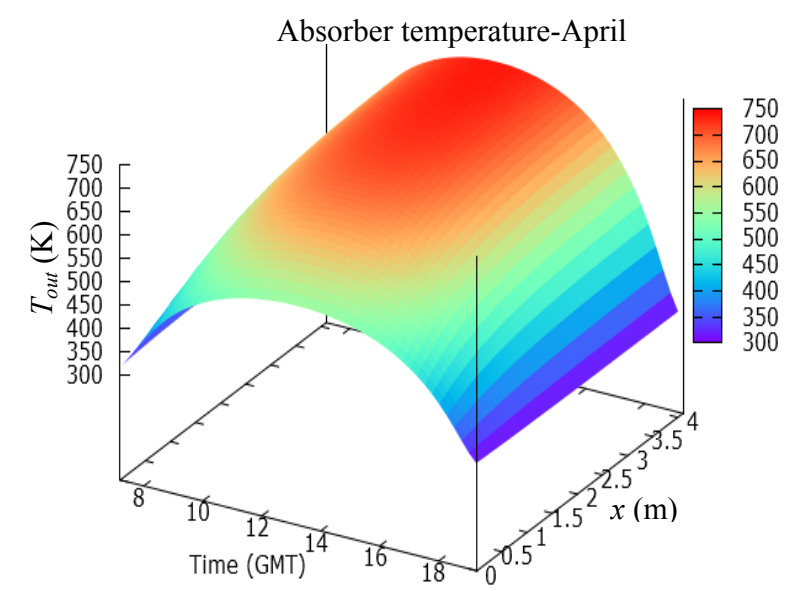

Fig. 7 Profile of $T_{p}$ in 3D during April. 
$11 \mathrm{GMT}$ and $15 \mathrm{GMT}$, and can reach $736 \mathrm{~K}$ allowing heating the fluid for thermodynamic use.

The air as a heat transfer fluid is free, simple and reliable for use with a reduced danger, and has little environmental impact. But like a lot of gas, it has a low capacity for heat transfer and its flow causes a lot of energy dissipations [16]. PT performances can be improved by preheating the input temperature of the fluid $T_{i n}$.

\section{Conclusions}

We have studied the influences of certain parameters on the behavior of a PT using the climatic conditions of Senegal. The solar resource in Senegal particularly during the sunniest season such as in April makes it easy to get temperatures superior to $673 \mathrm{~K}$, preliminary specifications for PT. Thermal storage or hybridization with another energy source is required in case of deficiency of radiation.

The concentrator must be composed of well reflective materials with high transmittance coefficient and protected against damage with better technical and economic compromise. The blocks must be properly assembled to avoid the geometrical losses and well set in tracking to avoid imperfections which can affect its operation.

The absorber must be a perfect conductor painted in black and be protected to prevent heat losses. Thus, the efficiency of the solar conversion to usable heat shall be improved.

It appears from this study, that to have output fluid temperatures usable for applications in thermodynamic solar, the length of the PT must be greater than $2.0 \mathrm{~m}$ in our climatic conditions. Also the optimal length of the PT can be set at $4.0 \mathrm{~m}$, because the longitudinal temperature variations of the $\mathrm{PT}$ and of the receiver are substantially zero beyond this length.

For this type of system, the turbulent flow regime for the transfer by forced convection between the wall and the fluid is more favorable, but the flow rates should be moderate or low.

The obtained results which depend on the model are encouraging, so it remains to test its validity in real situation. However, they are indicators that may lead to further studies such as improved optical and geometrical properties of the sensor.

The study of other specific components of a parabolic trough system is the next step in order to design a mini solar power plant, and to make a comparison with a PV system, biogas or diesel.

\section{References}

[1] Youm, I., Sarr, J., Sall, M., and Kane, M. 2000. "Renewable Energy Activities in Senegal." Renewable and Sustainable Energy Reviews 4 (1): 75-89.

[2] Alaphilippe, M., Bonnet, S., and Stouffs, P. 2007. "Low Power Thermodynamic Solar Energy Conversion: Coupling of a Parabolic Trough Concentrator and an Ericsson Engine." International Journal of Thermodynamics 10 (1): 37-45.

[3] Kelly, B., and Kearney, D. 2006. Parabolic Trough Solar System Piping Model. Technical report NREL (National Renewable Energy Laboratory)/SR-550-40165.

[4] Yaghoubi, M., Ahmadi, F., and Bandehee, M. 2013. "Analysis of Heat Losses of Absorber Tubes of Parabolic through Collector of Shiraz (Iran) Solar Power Plant." Journal of Clean Energy Technologies 1 (1): 33-7.

[5] Bonnet, S., Alaphilippe, M., and Stouffs, P. 2006. "Thermodynamic Solar Energy Conversion: Reflections on the Optimal Solar Concentration Ratio." International Journal of Energy, Environment and Economics 12 (3): 141-52.

[6] Pitz-Paal, R., Dersch, J., Milow, B., Tellez, F., and Ferriere, A. 2007. "Development Steps for Parabolic Trough Solar Power Technologies with Maximum Impact on Cost Reduction." Journal of Solar Energy Engineering 129 (4): 371-7.

[7] Liu, D., and Yu, L. 2011. "Single-Phase Thermal Transport of Nanofluids in a Minichannel." Journal of Heat Transfer 133 (3): 1-11.

[8] Rabadiya, A. V., and Kirar, R. 2012. "Comparative Analysis of Wind Loss Coefficient (Wind Heat Transfer Coefficient) for Solar Flat Plate Collector.” International Journal of Emerging Technology and Advanced Engineering 2 (9): 463-8.

[9] Conte, S. D., and De Boor, C. 1980. Elementary Numerical Analysis-An Algorithmic Approach. New York: McGraw-Hill Book Company.

[10] Mecibah, M. S., Boukelia, T. E., and Benyahia, N. E. 
2014. "Management and Exploitation of Direct Normal Irradiance Resources for Concentrating Solar Collectors: Algeria as a Case Study." International Journal of Energy and Environmental Engineering 6 (1): 65-73.

[11] IET (Institute for Energy and Transport). 2012. "Photovoltaic Geographical Information System." IET. Accessed March 7, 2014. http://re.jrc.ec.europa.eu/pvgis/.

[12] Mason, A., and Reitze, E. 2014. "Establishing Bankability for High Performance, Cost Reducing SkyTrough Parabolic Trough Solar Collector.” Energy Procedia 49 (June): 155-62.

[13] Sansom, C., Comley, P., Bhattacharyya, D., and Macerol, N. 2014. "A Comparison of Polymer Film and Glass Collectors for Concentrating Solar Power." Energy
Procedia 49 (June): 209-19.

[14] Abdullahi, B., Al-dadah, R. K., and Mouhmud, S. 2014. "Optical Performance of Double Receiver Compound Parabolic Concentrator." Energy Procedia 61 (January): 2625-8.

[15] Dermian, Y., Leon, J. F., and Dubovik, O. 2008. "Radiative Properties of Aerosol Mixture Observed during the Dry Season 2006 over M'Bour, Senegal." Journal of Geophysical Research 113 (D23): 1-15.

[16] Flamant, G., Gauthier, D., Benoit, H., Sans, J. L., Boissière, B., Ansart, R., and Hemati, M. 2014. "A New Heat Transfer Fluid for Concentrating Solar Systems: Particle Flow in Tubes." Energy Procedia 49 (June): 617-26. 